Supplement of Biogeosciences Discuss., 12, 14693-14738, 2015

http://www.biogeosciences-discuss.net/12/14693/2015/

doi:10.5194/bgd-12-14693-2015-supplement

(C) Author(s) 2015. CC Attribution 3.0 License.

(c) (1)

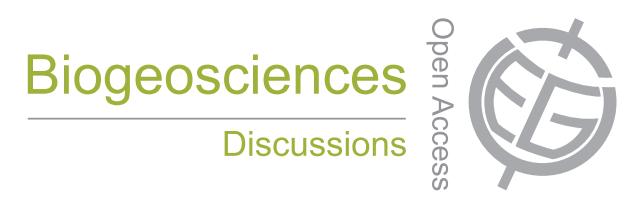

Supplement of

\title{
Automation of soil flux chamber measurements: potentials and pitfalls
}

\section{C.-M. Görres et al.}

Correspondence to: C.-M. Görres (carolyn.goerres@uantwerpen.be)

The copyright of individual parts of the supplement might differ from the CC-BY 3.0 licence. 


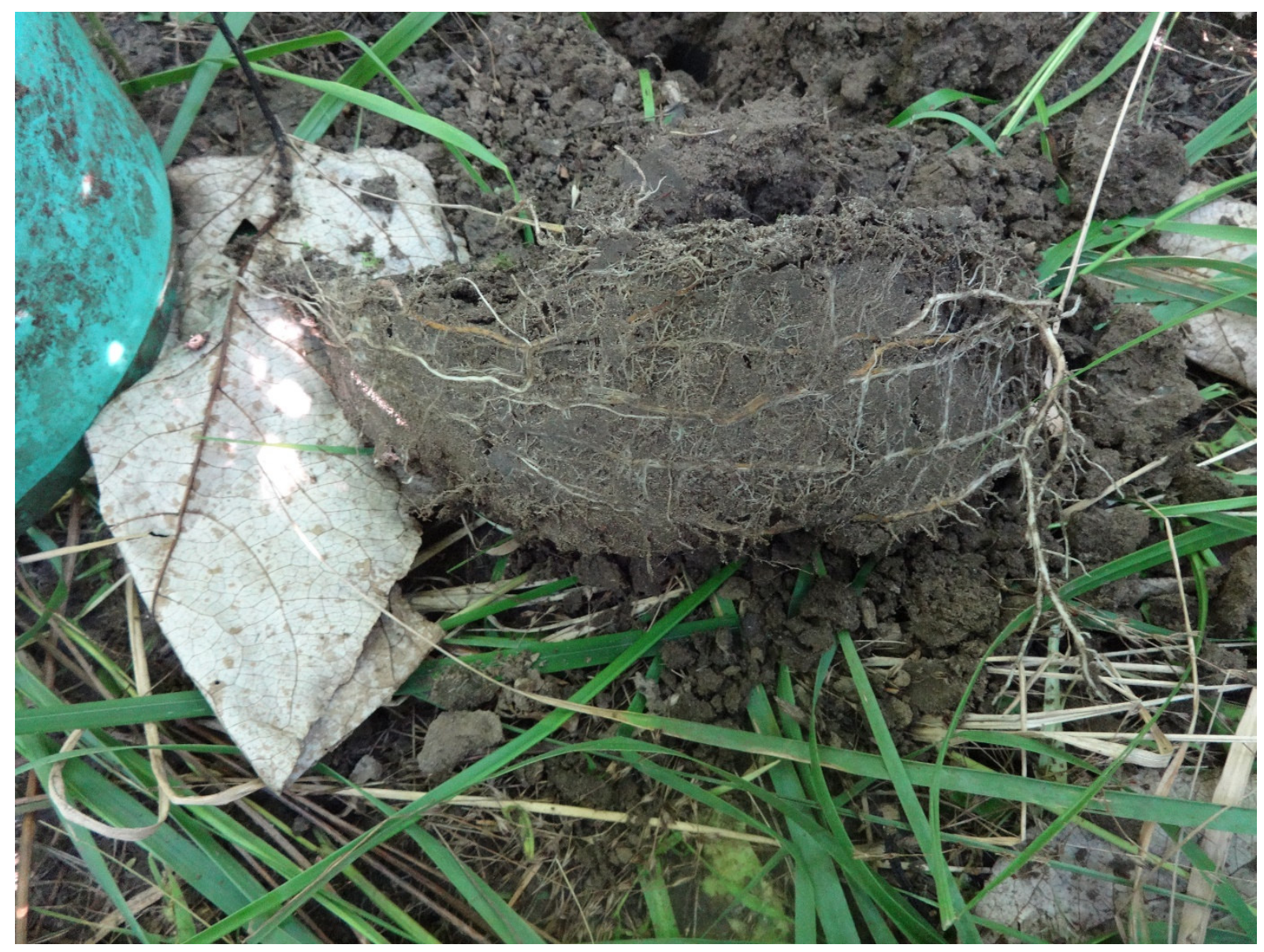

Figure S1. Newly developed root mat within a LI-8100A collar discovered after collar removal in August 2014. 


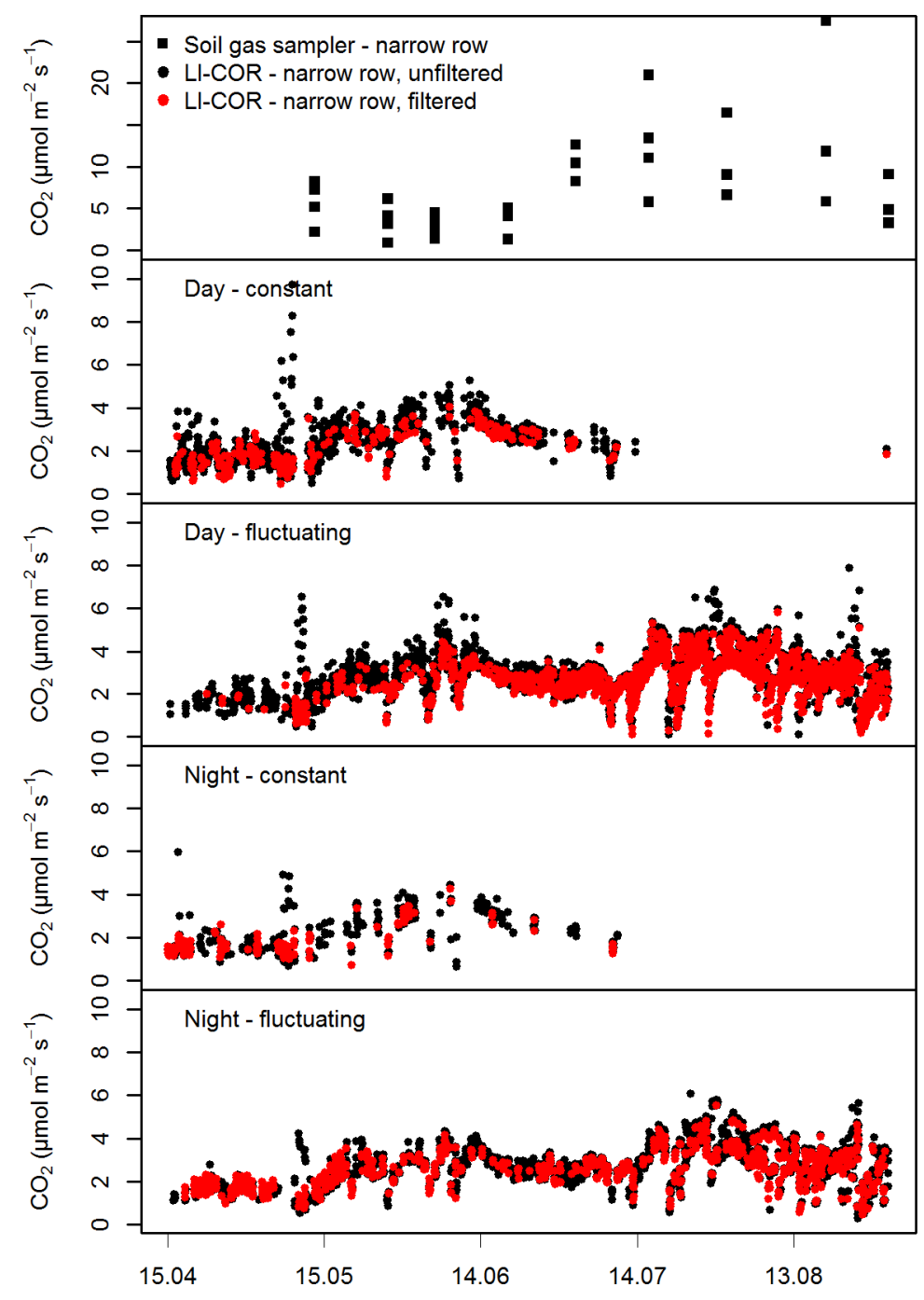

Figure S2. Soil gradient based $\mathrm{CO}_{2}$ fluxes and unfiltered chamber $\mathrm{CO}_{2}$ flux datasets for the entire monitoring period (narrow rows only). Carbon dioxide fluxes over time were grouped by time of the day and stability of the atmospheric $\mathrm{CO}_{2}$ concentration at $50 \mathrm{~cm}$ above the soil surface. The datasets were divided into day and night based on sun rise and sunset times. Atmospheric $\mathrm{CO}_{2}$ concentration was considered as constant when the standard deviation for a 3 min measurement prior to the chamber closures was $\leq 1.0 \mathrm{ppm}$. 